\title{
Design of Self-Assessment Tools to Measure Industry 4.0 Readiness. A Methodological Approach for Craftsmanship SMEs
}

\author{
R. Brozzi ${ }^{(1)}$, R. D. D’Amico ${ }^{(1)}$, G. Pasetti Monizza ${ }^{(1,2)}$, \\ C. Marcher $^{(1)}$, M. Riedl ${ }^{(1)}$, D. Matt ${ }^{(1,2)}$ \\ (1) Fraunhofer Italia Research, Bolzano, Italy; ${ }^{(2)}$ Free University of Bolzano, Bolzano, Italy; \\ riccardo.brozzi@fraunhofer.it
}

\begin{abstract}
The ongoing transition to digitalization will inevitably require companies to shift their manufacturing processes towards the Industry 4.0 paradigm, to remain competitive on the market. An increasing number of companies worldwide are initiating integrated 4.0 solutions, catching up with this revolution in the very concept of production processes and the dynamics among producers, suppliers and end-users. SMEs will be particularly challenged to integrate IT and automation to gain market segments in an increasingly globalised playing-field. SMEs will either seize it by identifying opportunities and risks or succumb it. Against the background that there is no such a thing as a one-size-fits-all solution on the way to Industry 4.0, the self-assessment of firmspecific starting circumstances is an essential step prior to any digital implementation. However, the analysis of a diverse pool of existing online selfassessment tools demonstrated main application fields in the context of large companies. This paper will present a methodology developed to design selfassessment tools for Industry 4.0 readiness level, in the framework of two publicly funded EU projects, targeting small-scale craftsmanship companies in the manufacturing and construction sector. The results indicate the importance to scale existing tools to the specific framework conditions of SMEs as well as valuable approaches and concrete recommendations to consider during the conceptual and design phase.
\end{abstract}

Keywords: Industry 4.0 · Self-Assessment Tool · Craftsmanship · SMEs.

\section{Introduction}

Industry 4.0 will lead to significant changes in the way of conceiving production along the entire value chain ultimately requiring companies to adapt existing business strategies and models [1] [2] [3]. In general, a change towards better networking and more flexible working is projected, concerning both the work processes as well as the

adfa, p. 1, 2011.

(c) Springer-Verlag Berlin Heidelberg 2011 
role of employees in the company [4] [3]. Through the introduction of Cyber-Physical Systems (CPS), which will be accompanied by Industry 4.0 (I4.0), employees and machines will, in future, work hand in hand on complex tasks. The emergence of such trends will require companies to tackle various challenges such as rethinking their production processes and dynamics along the entire supply chains, increasing their digitalization level as well as redefining the organization of tasks between humans and machines [5] [6]. Small- and medium-sized enterprises (SMEs) will be particularly challenged to adapt their current business strategies to I4.0, involving higher levels of industrial automation and information technologies. In fact, while several large companies have already anticipated the potential and risks of digitization and initiated innovation processes, on the other hand, SMEs are facing difficulties to adopt I4.0 solutions [7] [8]. SME specific challenges concern limited knowledge of I4.0 potential [9] [10], proper qualification of employees [11] [12] [13], lack of a comprehensive strategy [14], limited IT competences and technological knowledge [7] [5]. Hence especially in the starting phase, small companies need tailored external support to initiate innovation processes aimed at implementing I4.0 solutions [15]. To the extent that the focus of several companies in the near future will be oriented to I4.0, the assessment of their current willingness and ability to implement I4.0 solutions is compelling [16]. With respect to such an evidence, an increasing number of scholars claim a great need for a systematic approach to introduce I4.0 in enterprises respectively for a tool indicating the maturity level [17].

In the literature, several tools on this topic have been found, generally distinguishing between surveys such as self-assessment tools assessing the readiness [16] [18] [19] and maturity level [20] [21] [22] [23] [24] of firms toward radical technological and organisational changes. Schumacher et al. (2016) consider differences in the development stage as a reason justifying the adequacy of either readiness or maturity assessment tools, for firms at initial and advanced stages of strategic planning respectively. However, further research and tools addressing this topic have been mainly tailored to the characteristics and needs of large companies. Against the background that differentiated approaches to foster innovation in large and small companies exist [25] [26], this paper will explore the research question whether existing self-assessment tools match appropriately the requirements of SMEs and can hence accurately assess their readiness toward I4.0. The identification of the current development stage of SMEs toward I4.0 is essential to promptly recognize market opportunities, derive adequate business and production strategies. Notably, Schumacher et al. (2016) identified the need and developed new methods and tools to guide manufacturing companies aligning business strategies and operations. This paper, while affirming the validity of existing tools, attempted to scale the content and structure to the context and needs of SMEs. Furthermore, the approach employed to design a self-assessment tool tailored to the characteristics of small and medium craftsmanship enterprises will be presented. This entails, for instance, SMEs specific considerations which influenced the way in which questions were phrased, results displayed and communicated.

The paper is organised as follows. Following this introduction, the next section will provide a clear definition of the methods employed to derive a self-assessment tool 
tailored to the specific needs of small and medium craftsmanship companies. The results will firstly summarize the structure of the main existing self-assessment tools considered in the literature. Further analyses sampled the most recurring dimensions used across the selected self-assessment tools, providing a matching with current challenges SMEs should consider to this respect. Existing self-assessment tools were portrayed against number of dimensions and items to provide an overview of their respective complexity and enable their categorization. Finally, considering specific requirements of local craftsmanship companies, the resulting tailored self-assessment tool will be introduced and discussed with respect to previous scientific literature on the topic and useful recommendations for an effective design and presentation of results.

The proposed research provides local trade associations and regional business development agencies evidences on the design of tools assessing the industry 4.0readiness particularly in case of small and medium craftsmanship companies. The further development and application of such tools can result in an improved understanding of SME's development goals in industry 4.0, as well as define measures for supporting technology and knowledge transfer at regional level through the collaboration of trade association, companies and research institutes. The approach and findings presented in this study will also feed the scientific debate on this topic of growing research interest for universities, applied research institutes and business consulting agencies.

\section{Methodology}

The methodology employed to scale existing self-assessment tools to the needs of small-scale craftsmanship companies has been structured in three stages. In the first stage, a comprehensive literature review both in German and English language was conducted to identify existing self-assessment tools evaluating the readiness- and maturity-levels of firms toward industry 4.0 and digitalisation. In the second stage, metrics to classify the collected self-assessment tools were defined in terms of number of dimensions and item considered to derive a measure of their overall level of complexity (Fig. 1). Dimensions were considered expression of the overall degree of detail, i.e. higher number of dimensions accounts for a lower detail of the tool. This relation proved reasonable since a high amount of dimensions results in tools dealing with the assessment of several different areas of the company, without a detailed analysis of individual areas. Conversely, a lower amount of dimensions results in tools specifically assessing certain areas of the company, with a relatively high level of detail. Collected self-assessment tools were portrayed according to defined metrics. Number of items, instead, stand for the general complexity of the tool. In the literature items are also named as "maturity items" [23] referring to fields of analysis (e.g. Data security) within a specific dimension (e.g. Production). Tools with a high number of items, indeed, are time consuming. Considering the challenges facing SMEs identified in the literature review, in the third stage, a list of potential dimensions and items was created out of which the authors designed a self-assessment tool for industry 4.0 specifically 
tailored to the needs of craftsmen. Fig. 1 shows the two-axis diagram, where the horizontal axis identifies the dimensions, while the vertical one identifies the items. The area of the diagram can be split in 4 parts: (i) specific, few dimensions and high number of items. Tools in this area are designed for a specific kind of recipients, high degree of detail identified by the number of dimensions and deep analysis identified by the number of items. (ii) Comprehensive, high number of items and dimensions. Tools in this area are addressed to a general and wide comprehension of the recipients thanks to the high number of items spread in all dimensions. (iii) General, few items and high number of dimensions. Tools in this area have a generic approach, covering several dimensions with few items, a fast and generic tool. (iv) Selective, few dimensions and few items.

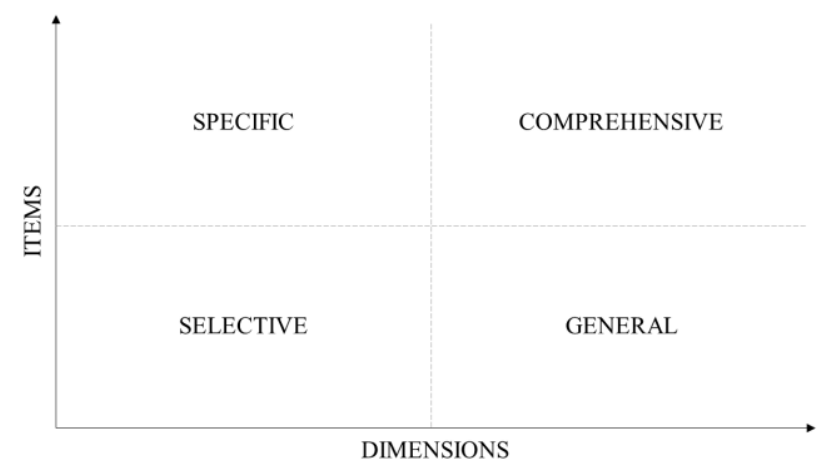

Fig. 1. Metrics analysis of the complexity of self-assessments

\section{Results}

\subsection{Literature review}

The primary focus of the literature review targeted industry 4.0 tools assessing the readiness of companies toward digitalisation and I4.0. The literature review was conducted both for I4.0 readiness as well as for digital maturity models. Schumacher et al (2016) notably clarified the difference between readiness and maturity in the matter that "readiness assessment takes place before engaging in the maturing process whereas maturity assessment aims for capturing the as-it-is state whilst the maturing process". Although such models have different characteristics and degrees of complexity [27], certain structures such as dimensions and items are recurrent. Dimensions can be considered process areas [27] namely aspects within the company to be assessed such as IT-Security, production processes and organisation. Items are detailed parts of each dimension to be assessed individually with respect to digitalisation. The latter case refers, for instance, to items such as implemented technologies, innovation management with respect to dimension such as organisation. 
After the exclusion of works that did not portray a necessary degree of detail of the number of dimensions and items, a total amount of 7 tools remained. These are characterized by a large variation with respect to both the number of dimensions and items (Table 1).

The existing maturity and readiness assessment tools range from 3 to 9 and from 7 to 62 in terms of dimensions and items respectively. Out of the 10 tools collected, 6 of them specifically targeted the assessment of the maturity of companies. The collected tools show a high degree of applicability across different sectors while scarce differentiation exists for SMEs and craftsmanship companies. Although not designed as maturity or readiness assessment tool, the "Checklist for process digitalisation" specifically targets craftsmen companies and comprises 9 dimensions and 63 items mainly composed of open text questions [28]. The mode of visualisation of results is not provided in detail. A similar example, also not specifically addressing industry 4.0 readiness level, is represented by the "Need-Analysis for Digital Craftsman" consisting of a questionnaire intended to provide craftsman businesses with information about the degree of digitisation in their company and potential for further development [28]. A study conducted by Telekom and techconsult, developed a digitalisation index considering the following dimensions: IT-Security, business model, customer relations, productivity [29]. This tool foresees the possibility to indicate whether the user belongs to a craftsmen company and access to survey to SMEs is not excluded. For such reasons, the Digitalisation index presents a suitable structure for the assessment of craftsmanship companies with respect to digitalisation.

Table 1. Existing Self-Assessment Tools.

\begin{tabular}{lll}
\hline \multicolumn{1}{c}{ Self-Assessment } & \multicolumn{1}{c}{ Developer } & \multicolumn{1}{c}{ Structure and Design } \\
\hline $\begin{array}{l}\text { IMPULS - Industrie 4.0 } \\
\text { Readiness }\end{array}$ & $\begin{array}{l}\text { VDMA, RWTH } \\
\text { Aachen, IW Consult }\end{array}$ & 6 dimensions, including 18 items. \\
\hline $\begin{array}{l}\text { Industry 4.0 - Digital } \\
\text { Operations Self-Assessment }\end{array}$ & $\begin{array}{l}\text { PricewaterhouseCo } \\
\text { opers }\end{array}$ & 6 dimensions, including 33 items. \\
\hline Benchmarking Readiness I4.0 & Fraunhofer ISI & 3 dimensions, including 9 items. \\
\hline I4.0 Reifegradmodell & FH-Oberösterreich & 3 dimensions, including 13 items. \\
\hline I4.0 Maturity Model & $\begin{array}{l}\text { Fraunhofer Austria; } \\
\text { Vienna University } \\
\text { of Technology }\end{array}$ & 9 dimensions, including 62 items. \\
\hline The Digital Maturity Model 4.0 & Forrester Research & 4 dimensions, including 28 items. \\
\hline The Digital Maturity Check & EY & 7 dimensions, including 14 items. \\
\hline Achieving Digital Maturity & Deloitte & 5 dimensions, including 35 items. \\
\hline Digitalisation Index & $\begin{array}{l}\text { Telekom- } \\
\text { techconsult }\end{array}$ & 4 dimensions, including 56 items \\
\hline $\begin{array}{l}\text { Digital Maturity Assessment } \\
\text { Test }\end{array}$ & Ericsson & 7 dimensions, including 7 items. \\
\hline
\end{tabular}


An emerging limit of such a tool is the scarce focus on industry 4.0, particularly compared to another valid conceptual tool for SMEs maturity assessment, namely the I4.0 Maturity Model [23]. Against this background, Table 2 provides an overview of specific challenges SMEs and related craftsmanship companies face with respect to frequently used dimensions of selected assessment tools. In fact, craftsmanship companies are potential profiteers of the digitalization [29] while facing analogous challenges of SMEs toward I4.0 and having at disposal few appropriate tools measuring their readiness and maturity levels. Besides relatively low number of employees and revenue level, making the majority of craftsman business belonging to SMEs, other aspects which need to be considered while developing self-assessment tools, characterize the craftsmanship sector, such as the predominant local structure of operations, limited technological production endowments and inseparable ownership and management structure [30] i.e. the owner acts simultaneously as operator of the company.

Table 2. Self-Assessment dimensions and related challenges to consider for SMEs

\begin{tabular}{llc}
\hline \multicolumn{1}{c}{ Dimension } & \multicolumn{1}{c}{ SMEs challenges } & Source \\
\hline Products and services & $\begin{array}{l}\text { Need to consider technology intelligence in } \\
\text { product engineering process }\end{array}$ & {$[31]$} \\
\hline Customer relation & Challenges along the entire supply chain; & {$[32][6]$} \\
\hline $\begin{array}{l}\text { Organisation/Knowledge } \\
\text { Management/Innovation } \\
\text { approach }\end{array}$ & $\begin{array}{l}\text { Scarce adoption of knowledge management } \\
\text { practices. }\end{array}$ & {$[33]$} \\
\hline Strategy/Leadership/Roadmap & $\begin{array}{l}\text { lack of a strategy, roadmap, business model } \\
\text { to I4.0. }\end{array}$ & {$[14] ;$} \\
& $\begin{array}{l}\text { lack of knowledge regarding the possibility } \\
\text { and potential of using the current technology. }\end{array}$ & {$[36]$} \\
\hline Production & $\begin{array}{l}\text { Improving existing IT infrastructure proved } \\
\text { costly for SMEs. }\end{array}$ & {$[37]$} \\
\hline IT-Security/Infrastructure & Proper qualification of employees required. & {$[38]$} \\
& Limited IT competence and knowledge. & {$[39][7]$} \\
\hline Employees & Expected frequent recourse to external & {$[14]$} \\
& expertise. & {$[14]$} \\
\hline $\begin{array}{l}\text { Ecosystem/Digital business } \\
\text { enablement }\end{array}$ & $\begin{array}{l}\text { Emerging legal challenges and risks not yet } \\
\text { fully tackled. Legal uncertainty. }\end{array}$ & {$[40]$} \\
\hline Legal and regulatory issue & & \\
\hline
\end{tabular}

Further analysis detected specific elements not fully considering SMEs as potential users of selected assessment tools. The well-designed tool developed by PriceWaterhouseCoopers to assess industry 4.0-readiness, for instance, does not permit to differentiate between small, medium and large enterprises, setting as the lowest annual revenue option a general value smaller than 100 Mio. Business processes may also differ substantially between SMEs and large companies, portraying questions 
about the use of application software such as ERP, MES, and CRM as inadequate [5] which are often mentioned in different tools. Lower emphasis should be devoted to leadership assessment considering the relatively simple structures recurring in craftsmanship companies.

On the base of the challenges and the insights discussed during expert interviews with representatives of the local craftsmen association, the following requirements for the design of the tool were also collected:

- Use of language avoiding too technical terms/concepts to enable users with limited knowledge of Industry 4.0 to complete the survey. Structure of the tool should be simple and limited compilation time required.

- Focus should regard current level of digitalisation under different perspectives (to assess readiness for digital transformation) and expected level in the future.

- Besides deriving digital level of companies, indication on application fields and typology of support required by research institutions and trade association should be assessed.

\subsection{Analysis of the self-assessment tools structures}

On the base of the metrics defined in the methodology, the different assessment tools were portrayed in a chart against the individual number of dimensions and items used, as illustrated in Fig. 2. Most of the assessment tools considered occupy the bottom right area i.e. tools offering a general overview across different process areas.

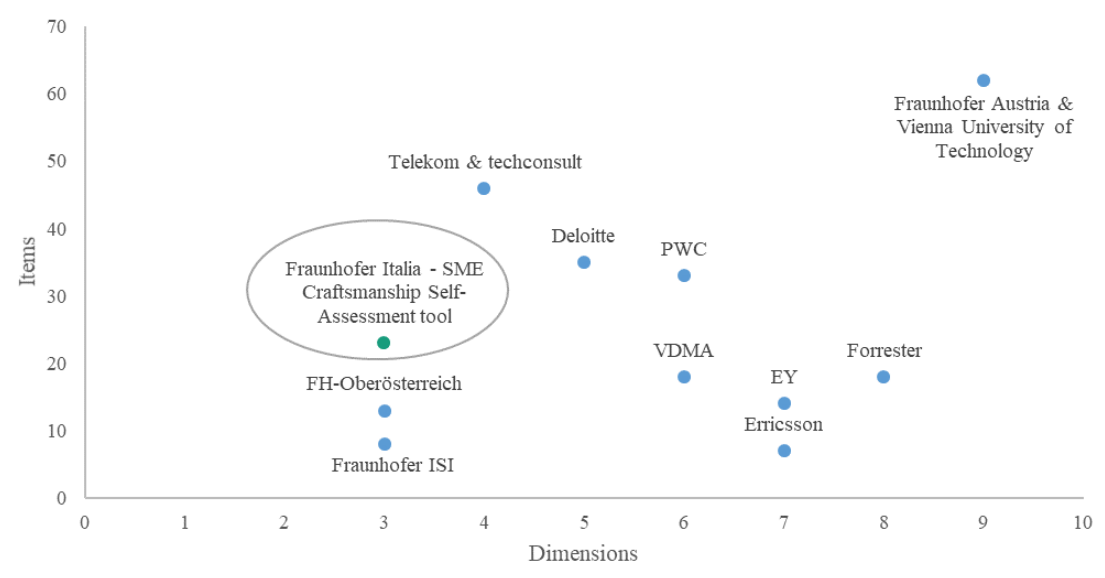

Fig. 2. Scatterplot items against dimensions in selected self-assessment tools.

The I4.0 Maturity Model developed by Fraunhofer Austria and the Vienna University of Technology positions itself on the upper right namely exhibiting a relatively high number of both items and dimensions. The structure and level of detail of this tool correspond to the comprehensiveness that tools encompassed within this area should exhibit. Remaining tools considered covered the bottom right area, expression of tools 
designed specifically on selected process areas with a relatively low level of detail of items foreseen. The characteristics of our tool developed for assessing SME Craftsmanship companies aimed at exhibiting a selective orientation. This is justified by the requirements previously identified for SME craftsmanship companies and particularly the need of simple structures enabling high participation of users in the compilation. Compared to the existing tools in this area, the analysis suggested sufficient room to deepen the assessment including additional items in the evaluation, without altering the selective orientation of the tool. In this regard, the tool acquires a relatively higher degree of accuracy, without assuming the complex structure that specific tool may entail.

\subsection{Definition of the self-assessment for craftsmen companies}

After having collected and defined categories in terms of characteristics of the individual self-assessment tools, together with the consideration of SMEs specific challenges in approaching digital transformation projects, the authors designed the structure of a self-assessment tool targeting SME craftsmanship companies (Table 3).

Table 3. Structure of SME Craftsmanship Self-Assessment tool

\begin{tabular}{|c|c|c|}
\hline Dimension & Item & Assessment \\
\hline \multirow{11}{*}{ 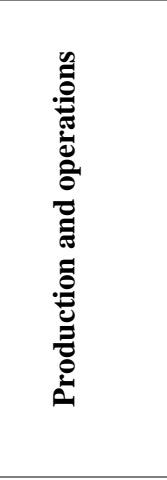 } & Use of digital devices in the company & - \\
\hline & Purpose to use the internet & $\bullet$ \\
\hline & Quality of internet connection & $\bullet$ \\
\hline & Data security & $\bullet$ \\
\hline & Distribution and typology of sales channels & $\bullet$ \\
\hline & Flexibility in producing products/offering services & $\bullet$ \\
\hline & Degree of digitalization of work processes & $\bullet$ \\
\hline & Perceived importance of new technologies & $\bullet$ \\
\hline & Use of software to analyse and collect data & $\bullet$ \\
\hline & Importance and utilization of collected data & $\bullet$ \\
\hline & Use of technologies related to I4.0 & $\bullet$ \\
\hline \multirow{9}{*}{ 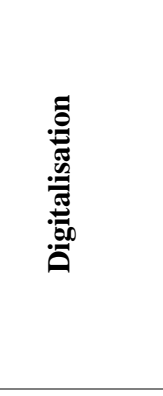 } & Perception of the trend digitalisation & $\bullet$ \\
\hline & Level of knowledge regarding I 4.0 & $\bullet$ \\
\hline & Perceived importance of I 4.0 for the company & $\bullet$ \\
\hline & Expected impact of I4.0 (company organisation) & $\bullet$ \\
\hline & Expected impact of I4.0 (competition, market demand) & $\bullet$ \\
\hline & Perceived advantages of I4.0 & \\
\hline & Perceived challenges of I4.0 & \\
\hline & Capabilities and qualifications of employees & $\bullet$ \\
\hline & Allocated resources for digitalization (EUR) & \\
\hline \multirow{3}{*}{ 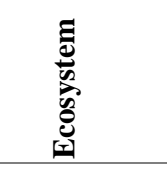 } & Collaboration with other institutions on I4.0 projects & $\bullet$ \\
\hline & Perceived assistance provided by supporting institutions & \\
\hline & Application field in which support to SMEs is required & \\
\hline
\end{tabular}

- Values considered to calculate average score determining the profile and attitude of users 
The number of dimensions was limited to 3 (Production and operations, Digitalisation, Ecosystem) with a total of 23 items. The evaluation of each item was based on a Likertscale ranging from 1 to 5 similarly to other tools. Items not included in the calculation were those considering the advantages and disadvantages of I4.0, the allocated resources for digitalisation, as well as the degree of collaboration with other institutions. Likewise, the item to assess the perception of support by institutions were excluded from the average calculation. While some tools considered a standard Likert-scale [23], others required a double compilation in terms of "Relevance for the firm" and "Realization in the firm" [29], the present self-assessment tool considered the approach proposed by PriceWaterhouseCooper in which user should state their perception in terms of the "current state" of the company and the "target state" the company aims to achieve in 5 years [18]. In the SME Craftsmanship Self-Assessment tool, the reference time-frames in which users should evaluate their digital level are named "current" and "expected" level of digitalisation. The scale for each item was distributed along 5 levels, the descriptions of the lowest and the highest ranks were described with individual examples depending on the item topic Table 4.

Table 4. Example of individual Likert-scale definition

Item: To what extent are digital devices used in your company?

Level 1: The company uses mainly PCs, laptops, printers and fax machines. New technologies are not being used.

Level 5: In addition to traditional devices such as PCs, laptops and printers, tablets, mobile phones (such as smartphones) and servers are used. The first $3 D$ printers, barcode scanners or smart glasses are also available.

The evaluation process considers separately the scores resulting from the average of values assigned as perception of the current state and those referring to the expected state to achieve in the future (Fig. 3).

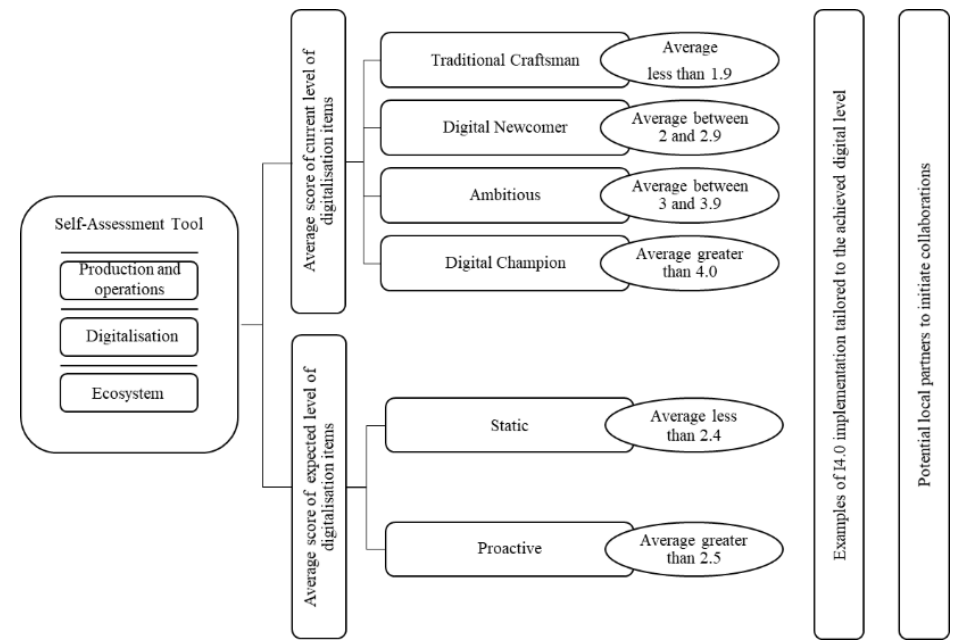

Fig. 3. Graphical representation Self-Assessment evaluation process 
The "current" average values serve to determine one of four levels of predetermined profiles of craftsman namely the Traditional Craftsman, the Digital Newcomer, Ambitious and the Digital Champion. The individual profile achieved according to the average score, is shown immediately after completion of the assessment and offers guidance and recommendations for digital actions from same or similar sector of the respondent. The "expected" average score serves to portray the attitude of responding craftsmen and thus measures the willingness to initiate projects of I4.0 applications in the company. The two resulting attitudes, depending on the average expected score achieved, can vary from Static to Proactive. Description of the resulting profile and attitude achieved are presented, together with examples of I4.0 implementation in companies operating in the same sector of the responding user and potential partners at local level supporting the company in creating a network to initiate concrete collaborations. In addition to the proposed scheme, the tool provides users with the possibility to display definitions (in form of a brief dictionary statement) for several technologies and I4.0 concepts. The visualization will consist of graphs, generated from the average values corresponding to the three dimensions, differentiating for the current and future digital level of the company.

\section{Discussion and conclusions}

\subsection{Results summary}

The present research is aimed at presenting the approach used to design a selfassessment tool to measure industry 4.0 readiness of SMEs and particularly those of craftsmanship nature. The analysis demonstrated the need to develop self-assessment tools specifically targeting SMEs, since existing tools may not have an adequate focus on the several challenges such entities face. However, the authors also acknowledge an increasing interest to scale existing tools to the requirements of SMEs, particularly from craftsmanship trade unions, national development agencies and research centres. While considering adaptation of the content (mainly scaled on the structure and level of operations), tools addressing SMEs should also foresee consideration of structure and design. To confer a relatively simple structure to the tool, as also requirements outlined, the selection of dimensions and items - with respect to Fig. 1- permitted to position the SME Craftsmanship Self-Assessment encompassing selective and specific features, avoiding a rather general and too detailed structure. General structures may not persuade users from SMEs about their utility, while time-consuming tools may not be fully considered. Furthermore, the use of simple wording in describing dimensions and items, possibility to visualise the definition of certain topics or technology, aided guidance on metrics proposed to measure readiness are considered means facilitating access of SMEs to the self-assessment tool. Furthermore, practical examples related to the achieved level of readiness including the description of real case technological implementation for a potential advancement are supposed to provide SMEs both an overview of their digital level, as well as insights on future steps to consider. Such 
examples were designed to be displayed according to the sector of the user, to stimulate interest and motivation.

\subsection{Future work}

The presented findings result from the activities carried out in the framework of two publicly funded projects from the European Regional Development Fund, namely I4.0 Roadmap (B53D07000290008) and CRAFTech (B56G17000000008). The latter project recently released a free online survey encompassing the dimensions and items, described in the proposed SME Craftmanship Self-Assessment. The analysis of results derived from the assessment completed by representatives of local companies represents a reasonable follow up of the present research. It will aim at presenting the digital readiness level of local craftsman companies as well as potential application fields and typology of support required to support SMEs along the digital transformation. On the base of the feedback from respondents on the structure and contents of selected dimensions and items, further research will attempt determining the level of compliance of the SME Craftmanship Self-Assessment tool and related design features (such as concrete examples, glossary function, etc.) to the specific requirements of SMEs. In this regard, further methods and concepts need to be developed, to derive useful information from users contributing to the continuous improvement of such tools for SMEs. Furthermore, future works should encompass the analysis of additional aspects indicating internal and external readiness level, such as the willingness to share information and awareness of data security protocols.

\section{$5 \quad$ References}

[1] W. MacDougall, "Industrie 4.0 - Smart Manufacturing for the Future.," Trade \& Invest, Berlin, 2014.

[2] E. Peß1 and W. Ortner, "Industrie 4.0 - Informationstechnologie verschmilzt mit Produktion," Productivity Management, pp. 59-62, 2014.

[3] D. Spath, O. Ganschar, S. Gerlach, M. Hämmerle, T. Krause and S. \& Schlund, "Produktionsarbeit der Zukunft - Industrie 4.0," Fraunhofer IAO (Institut für Arbeitwirtschaft und Organisation), Stuttgard, 2013.

[4] E. Rauch, P. Dallasega and D. Matt, "Critical Factors for Introducing Lean Product Development to Small and Medium sized Enterprises in Italy. Elsevier,", Procedia CIRP, vol. 60, pp. 362-367, 2017.

[5] M. Gabriel and E. Pessl, "Industry 4.0 and suitability impacts. critical discussion of suitability aspects with a special focus on future of work and ecological consequences," Annals of the Faculty of Engineering Hunedoara - International Journal of Engineering, pp. 131-136, 2016. 
[6] D. Matt and E. Rauch, "Chancen zur Bewältigung des Fachkräftemangels in KMU durch Urbane Produktion von morgen," W. Kersten, H. Koller, \& H. Lödding, Industrie 4.0 Wie intelligente Vernetzung und kognitive Systeme unsere Arbeit verändern (pp 155-176), Berlin, 2014.

[7] M. Dassisti, H. Panetto, M. Lezoche, P. Merla, C. Semeraro, A. Giovannini and M. Chimienti, "Industry 4.0 paradigm: The viewpoint of the small and medium enterprises," in 7th International Conference on Information Society and Technology (pp. 50-54), Kopaonik, Serbia, 2017.

[8] J. Schmeiss and M. Dopfer, "Die digitale Geschäftsmodell-Transformation - Chancen, Risiken und Strategien für den deutschen Mittelstand," Mittelstand-Digital. Wissenschaft trifft Praxis. Digitale Geschäftsmodelle: Erfolgsfaktoren und Praxisbeispiele (pp. 7-13). Bad Honnef: Begleitforschung Mittelstand-Digital WIK, 2017.

[9] S. Wischmann, L. Wangler and A. Botthof, "Industrie 4.0: Volks- und betriebswirtschaftliche Faktoren für den Standort Deutschland," 2015.

[10] L. Sommer, "Industrial Revolution - Industry 4.0: Are German Manufacturing SMEs the First Victims of this Revolution?," ournal of Industrial Engineering and Management, vol. 8, no. 5, pp. 12-32, 2015.

[11] Universität Bremen, "Industrie 4.0 - Auswirkungen auf Aus- und Weiterbildung in der M+E Industrie," Die bayerischen Metall- und Elektro-Arbeitgeber, 2016.

[12] PricewaterhouseCoopers, "Industry 4.0: Building the Digital Enterprise," 2016.

[13] McKinsey\&Company, "Industry 4.0 How to navigate Digitization of the manufacturing sector. McKinsey Digital.," 2015.

[14] C. Schröder, "The Challenges of Industry 4.0 for Small and Medium-sized Enterprises," 2016.

[15] D. Kochan and R. Miksche, "Advanced Manufacturing and Industrie 4.0 for SME. Newtech," in 5th International Conference on Advanced Manufacturing Engineering and Technologies, 2017.

[16] K. Lichtblau, V. Stich, R. Bertenrath, M. Blum, M. Bleider, A. Millack, K. Schmitt, E. Schmitz and M. Schröter, "Industrie 4.0 - Readiness," Stiftung für den Maschinenbau, den Anlagenbau und die Informationstechnik (VDMA), Aachen, Köln, 2015.

[17] E. Pessl, S. Sorko and B. Mayer, "Roadmap Industry 4.0 - Implementation Guideline for Enterprises," International Journal of Science, Technology and Society, vol. 5, no. 6, pp. 193-202, 2017.

[18] PricewaterhouseCoopers, "Industry 4.0 - Digital Operations Self-Assessment.," 2016.

[19] Fraunhofer ISI, "Internet-based self-assessment instrument Industrie 4.0 for Baden-Württemberg," Fraunhofer-Gesellschaft, 2015. [Online]. Available: https://www.isi.fraunhofer.de/. [Accessed 10 March 2018]. 
[20] G. C. Kane, D. Palmer, A. N. Phillips, D. Kiron and B. N, "Achieving Digital Maturity. Adopting your company to a changing world," MISSIoan Management Review and Deloitte University Press, 2017.

[21] Ernst \& Young, "Digital Maturity Check," [Online]. Available: https://digitalmaturitycheck.ey.com/. [Accessed 10 March 2018].

[22] Forrester Research, "The Digital Maturity Model 4.0,” 2016.

[23] A. Schumacher, S. Erol and W. Sihn, "A maturity model for assessing Industry 4.0 readiness and maturity of manufacturing enterprises," Procedia CIRP, vol. 52, pp. 161-166, 2016.

[24] G. Schuh, R. Anderl, J. Gausemeier, M. ten Hompel and W. Wahlster, "Industrie 4.0 Maturity Index. Managing the Digital Transformation,” Herbert Utz Verlag, Munich, 2017.

[25] C. Rammer and R. Frietsch, "Global Champions und Hidden Champions: Internationale Konzerne und KMU im Innovationswettbewerb," Fraunhofer ISI, Karlsruhe, 2015.

[26] A. Spithoven, W. Vanhaverbeke and N. Roijakkers, "Open innovation practices in SMEs and large enterprises," Small Business Economics, vol. 41, no. 3, pp. 537-562, 2013.

[27] A. D. Carolis, M. Macchi, M. P. Brundage and S. Terzi, "Maturity models and tools for enabling Smart Manufacturing Systems: comparison and reflections for future developments," in IFIP 14th International Conference on Product Lifecycle Management, Seville, 2017.

[28] Handwerkskammer Koblenz-Kompetenzzentrum Digitales Handwerk Schaufenster West, "www.handwerkdigital.de," 1005 2017. [Online]. Available: https://handwerkdigital.de/. [Accessed 8 March 2018].

[29] Deutsche Telekom, "Der digitale Status Quo im Handwerk," 2016.

[30] Cr@ftsman Project, "Report on the situation of craftsmanship in Europe," 2011.

[31] Placzek, Eberling and Gausemeier, "Conception of a Knowledge Management System for Technologies," in International Association for Management Technology (IAMOT 2015), 2015.

[32] Pfohl, Yashi and Kurnaz, "The Impact of Industry 4.0 on the Supply Chain," in Hamburg International Conference on Logistics, 2015.

[33] R. Cerchione and E. Esposito, "Using Knowledge Management Systems: A Taxonomy os SME Strategies," International Journal of Information Management, vol. 37, no. 1B, pp. 1551-1562, 2017.

[34] V. Rudtsch, J. Gausemeier, J. Gesing, T. Mittag and S. Peter, "Patternbased Business Model Development for Cyber-Physical Production Systems," Procedia CIRP, vol. 25, pp. 313-319, 2014. 
[35] H. Kagermann and W. Wahlster, "Recommendations for implementing the strategic initiative Industrie 4.0," acatech - National Academy of Science and Engineering, 2013.

[36] M. Andulkar, D. T. Le and U. Berger, "A multi-case study on Industry 4.0 for SME's in Brandenburg, Germany," in Proceedings of the 51st Hawaii International Conference on System Sciences, Hawaii, 2018.

[37] Deloitte, "Challenges and solutions for the digital transformation and use of exponential technologies," Zurich, 2015.

[38] W. Bauer, S. Schlund, D. Marrenbach and O. Ganshar, Industrie 4.0 Volkswirtschaftliches Potenzial für Deutschland, Bundesverband Informationswirtschaft Telekommunikation und neue Medien e. V., 2014.

[39] K. Grass and E. Weber, "EU 4.0 - The debate on digitalisation and the labour market in Europe," Institute for Employment Research of the Federal Employment Agency, 2016.

[40] I. Plöger, J. C. Sahl, H. Willems, P. Bräutigam, C. Hinerasky and T. (. Klindt, "Industrie 4.0 - Legal challenges of digitalisation. An input for the public debate.," Bundesverband der Deutschen Industrie e. V., Berlin, 2015.

[41] Austrian Federal Ministry of Science Research and Economy, "Study on traditional craftsmanship," 29 August 2017. [Online]. Available: https://www.bmwfw.gv.at/Unternehmen/UnternehmensUndKMU-Politik/Seiten/Studie-Traditionelles-Handwerk.aspx. 